\title{
The role of the ventricular assist device coordinator: quo vadis?
}

\author{
Sarah E. Schroeder ${ }^{1}$, Silvia Boschi ${ }^{2}$, Thomas Schlöglhofer ${ }^{3}$ \\ ${ }^{1}$ Bryan Heart, Division of MCS Therapy, Lincoln, NE, USA; ${ }^{2}$ S. Orsola-Malpighi University Hospital, Heart Failure and Transplant Center, \\ Bologna, Italy; ${ }^{3}$ Center for Medical Physics and Biomedical Engineering, Medical University of Vienna, Austria; Division of Cardiac Surgery, \\ Medical University of Vienna, Vienna, Austria; Ludwig-Boltzmann-Institute for Cardiovascular Research, Vienna, Austria \\ Correspondence to: Sarah E. Schroeder. Bryan Heart, $160048^{\text {th }}$ Street Ste 600, Lincoln, NE 68521, USA. Email: sarah.schroeder@bryanheart.com.
}

Submitted Sep 25, 2020. Accepted for publication Mar 02, 2021.

doi: $10.21037 /$ acs-2020-cfmcs-17

View this article at: http://dx.doi.org/10.21037/acs-2020-cfmcs-17

\section{Introduction}

The history of ventricular assist device (VAD) therapy is well documented, dating back to the first implanted device in 1966 by Dr Michael DeBakey (1). The history of the VAD coordinator, however, lacks documentation secondary to an inconsistent role definition in the literature. The first documentation of nurses measuring artificial heart data by waveforms was in 1988 (2). In the 1990s as devices became commercially available, the role of the VAD coordinator came to fruition to connect the mechanics of the devices and the medical care aspect of the patient (3). Oftentimes it is said "There is no VAD patient without a VAD coordinator", paving the way to the role itself.

One consistent aspect of the VAD coordinator role is to evaluate technical information to support clinical decisions. Varying structure amongst VAD programs lead to different day-to-day duties of a VAD coordinator (3). Anticoagulation monitoring, direct patient care, education and program compliance monitoring are some of the numerous duties the VAD coordinator integrates into VAD programs (4). The VAD coordinator is the central figure in a multidisciplinary VAD team, interacting directly with all specialized disciplines who are involved in VAD recipient care.

The International Consortium of Circulatory Assist Clinicians (ICCAC) was established in 2007 to provide a professional society platform for non-physician clinicians in the VAD community. Its establishment allows for collaboration, research development, and educational support in the advancement of VAD technology (5). The professional backgrounds of VAD coordinators differ between the United States (US), European, Asian and Canadian programs and may consist of nursing, perfusion, advanced practice, biomedical engineering and medicine (6). As a result of this professional variety, the VAD coordinator role remains uncertified, with no validation of the vast knowledge needed to care for VAD patients. ICCAC was pivotal in describing survey results of VAD coordinator responsibilities, which was the first of its kind (3). However, literature remains lacking with regards to outcomes in centers using VAD coordinators.

\section{Evolution of the VAD coordinator}

The VAD coordinator role is a key component of the inpatient multidisciplinary team in caring for VAD recipients. The role has evolved to meet the needs of the team and provide consistency of care within VAD programs. (7). International survey of VAD coordinators identified more emphasis towards the number of duties, rather than 'coordinator to patient ratios' alone. Scope of duties in current day practice include education, hospital coverage, 24/7 on-call, operating room management, regulatory compliance and equipment oversight (8). There is $100 \%$ utilization of the VAD coordinator role amongst centers in the United States (US) compared to only $70 \%$ utilization of this role at non-US centers. More importantly, over half of the VAD coordinators surveyed described working up to fifty-five hours of overtime per month regardless of salary status, illustrating an extensive burden on VAD coordinators across all programs. Ratios of coordinators to VAD recipients varied greatly from center to center, where the average ratio was one clinician to ten patients, with the highest reported as one clinician to twenty-five patients (9).

A particular concern described in the literature is 
the dramatic differences between programs in terms of definition, role, workload and burden these responsibilities place on the VAD coordinator regardless of geographic location. Such differences add to the wide variance of training amongst coordinators and demonstrates the lack of available certification for VAD coordinators. This also suggests the need for specialized and official training for VAD coordinators to allow for standardization across all VAD programs. Particularly in Europe, multiple healthcare systems and languages pose further challenges in this process. To assist in standardization, ICCAC and University of Michigan (USA) are currently collaborating on an international-based VAD clinician certification examination to validate the educational needs of a VAD coordinator along with others who care for VAD patients. This is the first certification of its kind in this field and is much needed for ongoing advancement, support and validation of this role.

\section{The future of the VAD coordinator}

The VAD coordinator as a professional figure is instrumental in the future of the fully implantable left ventricular assist device (LVAD). The knowledge and skillset of the VAD coordinator is integral in ensuring optimal VAD functionality and advancing future technological advancements. The LVAD team involves collaboration between many members including VAD coordinators, biomedical engineers, data managers and clinicians. The knowledge and skillset of the VAD coordinator is paramount in this multidisciplinary team interaction.

The world of mechanical support is constantly evolving, which is necessary for device improvements. VAD coordinators can expect further changes to their role through the use of telemonitoring. The large amount of data will require review by experienced clinicians or intelligent algorithms to detect potential adverse events; both a blessing and a curse. Following the development of fully implantable devices, and in the face of a global pandemic, remote monitoring could bridge the need for VAD patient evaluation while ensuring safety for all stakeholders in VAD programs. However, devices of this nature have yet to be proven to be clinically reliable.

\section{Conclusions}

The continuing evolution of VADs serves to be of benefit to the advanced heart failure patient. While the race for the first "successful" fully implantable and durable VAD is ongoing, many VAD coordinators describe concerns regarding problems with the external equipment; raising questions as to whether placing these pumps internally is the solution. Nevertheless, in the coming years pumps will continue to advance, and remote telemonitoring will be instrumental in providing efficiency to the VAD coordinator role and, thus, decrease adverse events. The VAD coordinator is imperative to the success of VAD programs internationally regardless of the individual's professional background. The goal of VAD clinician certification is to continue to validate the education required to be a VAD coordinator. The future of the VAD coordinator will continue to evolve based upon the needs of the programs and the patients served.

\section{Acknowledgments}

Funding: None.

\section{Footnote}

Conflicts of Interest: SES: ICCAC 2020 Secretary and Research Committee Chair (no compensation for these roles), ICCAC 2020 Research Grant Recipient; SB: ICCAC member; TS: Past president of ICCAC; Consultant for Abbott and Medtronic Inc.; Research grant from Medtronic Inc.

Open Access Statement: This is an Open Access article distributed in accordance with the Creative Commons Attribution-NonCommercial-NoDerivs 4.0 International License (CC BY-NC-ND 4.0), which permits the noncommercial replication and distribution of the article with the strict proviso that no changes or edits are made and the original work is properly cited (including links to both the formal publication through the relevant DOI and the license). See: https://creativecommons.org/licenses/by-nc-nd/4.0/.

\section{References}

1. Gemmato CJ, Forrester MD, Myers TJ, et al. Thirtyfive years of mechanical circulatory support at the Texas Heart Institute: an updated overview. Tex Heart Inst J 2005;32:168-77.

2. Henker RA, Smith RG, Murdaugh C. Effects of nursing interventions on cardiac output in the patient with a total artificial heart. J Cardiovasc Nurs 1988;2:56-67.

3. Christensen D M, VanderPluym C, Conway J, et al. 
Outpatient management: The role of the VAD coordinator and remote monitoring. In: Montalto A, Loforte A, Musumeci F, et al. Mechanical Circulatory Support in End-Stage Heart Failure. Springer, Cham; 2017.

4. Schlöglhofer T, Robson D, Bancroft J, et al. International coordinator survey results on the outpatient management of patients with the HeartWare® ventricular assist system. Int J Artif Organs 2017;39:553-7.

5. International Consortium of Circulatory Assist Clinicians (ICCAC). Bringing together the knowledge and experience of MCS professionals. 2020. Available online: https://iccac. global/about/iccac

6. Schlöglhofer T, Adams J, Combs P. International VAD coordinator practices: clinical utility and application of HeartWare HVAD system waveforms and logfiles. Int J

Cite this article as: Schroeder SE, Boschi S, Schlöglhofer T. The role of the ventricular assist device coordinator: quo vadis? Ann Cardiothorac Surg 2021;10(3):386-388. doi: 10.21037/acs2020-cfmcs-17
Artif Organs 2017;40:433-4.

7. Feldman D, Pamboukian SV, Teuteberg JJ, et al. The 2013 International Society for Heart and Lung Transplantation Guidelines for mechanical circulatory support: executive summary. J Heart Lung Transplant 2013;32:157-87.

8. Schroeder SE, Baker M. Differences in mechanical circulatory support programmatic make-ups: Defining delineation of duties. Abstract Poster Presentation, ASAIO 2019 Scientific Session, San Francisco, CA, USA. 2019.

9. Horvat J, Neiger O, Christensen D, et al. International VAD coordinator team composition: The role of the advanced nurse practitioners in VAD teams. Abstract Poster Presentation, ASAIO 2017 Scientific Session, Chicago, IL, USA. 2017. 